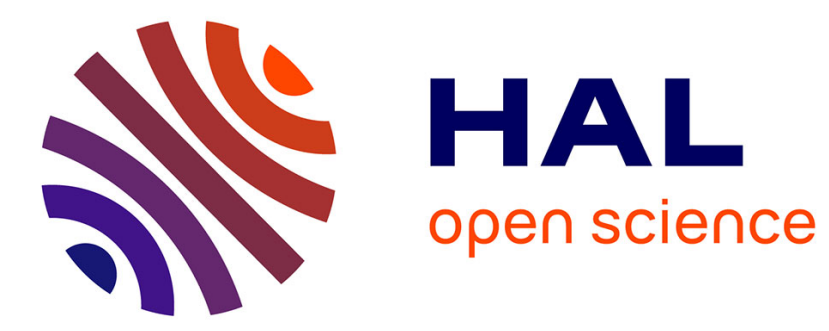

\title{
Partial Splitting of Longevity and Financial Risks: The Longevity Nominal Choosing Swaptions
}

Harry Bensusan, Nicole El Karoui, Stéphane Loisel, Yahia Salhi

\section{To cite this version:}

Harry Bensusan, Nicole El Karoui, Stéphane Loisel, Yahia Salhi. Partial Splitting of Longevity and Financial Risks: The Longevity Nominal Choosing Swaptions. Insurance: Mathematics and Economics, 2016, 68 (May 2016), pp.61-72. hal-00768526

\section{HAL Id: hal-00768526 \\ https://hal.science/hal-00768526}

Submitted on 21 Dec 2012

HAL is a multi-disciplinary open access archive for the deposit and dissemination of scientific research documents, whether they are published or not. The documents may come from teaching and research institutions in France or abroad, or from public or private research centers.
L'archive ouverte pluridisciplinaire HAL, est destinée au dépôt et à la diffusion de documents scientifiques de niveau recherche, publiés ou non, émanant des établissements d'enseignement et de recherche français ou étrangers, des laboratoires publics ou privés. 


\title{
Partial Splitting of Longevity and Financial Risks: The Longevity Nominal Choosing Swaptions.*
}

\author{
Harry BENSUSAN ${ }^{\dagger}$, Nicole EL KAROUI ${ }^{\dagger \ddagger}$, Stéphane LOISEL ${ }^{\S}$ \\ and Yahia SALHI ${ }^{\S}$
}

December 21, 2012

\begin{abstract}
In this paper, we introduce a new structured financial product: the so-called Life Nominal Chooser Swaption (LNCS). Thanks to such a contract, insurers could keep pure longevity risk and transfer a great part of interest rate risk underlying annuity portfolios to financial markets. Before the issuance of the contract, the insurer determines a confidence band of survival curves for her portfolio. An interest rate hedge is set up, based on swaption mechanisms. The bank uses this band as well as an interest rate model to price the product. At the end of the first period (e.g. 8 to 10 years), the insurer has the right to enter into an interest rate swap with the bank, where the nominal is adjusted to her (re-forecasted) needs. She chooses (inside the band) the survival curve that better fits her anticipation of future mortality of her portfolio (during 15 to 20 more years, say) given the information available at that time.

We use a population dynamics longevity model and a classical two-factor interest rate model to price this product. Numerical results show that the option offered to the insurer (in terms of choice of nominal) is not too expensive in many real-world cases. We also discuss the pros and the cons of the product and of our methodology. This structure enables insurers and financial institutions to remain in their initial field of expertise.
\end{abstract}

Keywords: Pension funds, longevity risk, interest rate risk, risk transfer, longevity modeling, hedge effectiveness.

${ }^{*}$ This work was supported by the research chair Dérivés du Futur sponsored by the Fédération Bancaire Française and by the research chair Actuariat Durable sponsored by Milliman Paris. The authors thank Caroline Hillairet for her help to improve the paper, as well as Alexandre Boumezoued for useful comments and CA CIB for access to pricing software.

${ }^{\dagger}$ CMAP, Ecole Polytechnique, 91128, Palaiseau, Cedex

${ }^{\ddagger}$ LPMA, Université Pierre et Marie Curie, 4 Place Jussieu, 75005, Paris

${ }^{\S}$ Université de Lyon, Université Lyon 1, ISFA, 50 Avenue Tony Garnier, F-69007 Lyon, France. 


\section{Introduction}

Annuity providers like life-insurance companies and pension funds have to manage longevity (biometric) risk, but also associated financial risks, because a significant part of the assets of the insurer corresponds to bonds with long maturities for some of them. Consequently, interest rate risk is very often the most important financial risk associated with traditional pension portfolios, even if some products like variable annuities are subject to many other market risks and to policyholder behavior risk (see e.g. Nguyen (2011)), and in particular to mass surrender risk (see Loisel and Milhaud (2011)).

Some financial products like longevity swaps, $q$-Forwards, or longevity bonds have been proposed and are theoretically useful to manage pure longevity risk and financial risks (see Blake et al. (2006), Menoncin (2008), Barrieu et al. (2012) for more details on those products). However, so far, only (customized or standardized) private transactions have been successful. Indeed, investors are reluctant to take long term risks, i.e maturities exceeding 25 years, which limits potential investors in such market to the reinsurance industry, and thus excludes naturally the access to financial markets. Besides, the absence of a unique longevity index is an obstacle for the development of liquid and tradable transactions. Hence, such contracts cannot be set up without a common longevity benchmark that satisfies all market stakeholders.

Further significant barriers to longevity transfer rely on the difficulties surrounding the pricing of such securities. Barrieu et al. (2012) argues that risk-neutral valuation is inappropriate because of illiquidity and incompleteness of the longevity risk market. However, indifference pricing would probably be a good way to tackle this issue, but yields to more expensive prices. We should also mention that basis risk is very often present in those contracts, because payoffs are usually based on national population indices that can evolve very differently from the ones of the insurance portfolio, see Salhi and Loisel (2011). Therefore, indemnity-based payoffs are difficult to set up due to the lack of transparency for investors, who are likely to be afraid of asymmetry of information. Finally, for such transfers, counterparty risk is particularly important due to long maturities, and the recent crisis does not facilitate the emergence of a longevity market, see e.g. Biffis et al. (2011) and (Biffis and Millossovich 2012).

It thus seems more feasible in the short term to enable the insurer exposed to longevity risk to transfer most of the associated financial risk and to keep (mostly) pure biometric longevity risk that she is used to manage and that can be (partially) mutualized with mortality risk and some other insurance risks. For pension plans, the low-interest-rate environment introduces higher discounting factors and thus increases the present value of future cash-flows to be paid to pensioners. Even if in some countries the best estimate of liabilities may be computed with a regulatory discounting rate different from the financial discounted rate obtained by yield curves, low interest rates constitute a big economic issue, and also increase the potential effect of unexpected longevity improvements. If we neglect complex life insurance accounting 
aspects, we might consider that the insurer borrowed some money to the annuitant at a fixed rate, which is closely related to discounting factors used to compute the premium paid by the policyholder. Given her exposure to the bond market on the asset side of the balance sheet, the insurer faces the risk that interest rates become too low to finance the cash-flows. The insurer could try to manage this exposure with a strategy that includes a combination of interest rate swaps with different maturities that try to match the expected cash-flow structure of the insurance portfolio. The insurer wants to receive the fixed leg (which corresponds to what she has to pay to annuitants), and to pay the floating leg (that corresponds to what she is supposed to obtain from her investment strategy).

The problem is that this protection is imperfect, because the "size" of the required protection (which is related to the nominal structure) is not known yet and depends on future longevity of the policyholders. In this paper, we introduce a toy financial product that may enable insurers to better manage interest rate risks associated with annuity portfolios: with the socalled Longevity Nominal Choosing Swaption (LNCS), the insurer can choose after a first period the nominal structure that best matches her current anticipation of the evolution of the longevity of her portfolio, within two boundaries corresponding to extreme scenarios in terms of biometric longevity risk. These limits can be chosen by the insurer at the initial date from quantiles of some stochastic mortality model. The distance between those limit curves must be large enough to provide a real protection. To avoid prohibitive costs, this distance cannot be extremely large because the bank logically prices the product using the worst-case scenario. Another advantage of the proposed product LNCS is that the bank can sell a "pure" financial product (without biometric risk) that she is used to manage. The bank does not have to believe in the stochastic mortality model used by the insurance company, because her pricing could be operated on the basis of the worst-case scenario.

A straightforward question is the following: with LNCS the insurer is now able to hedge her interest rate risk in a more dynamic way; however, to have the guarantee to be able to be protected in the future, she purchases an option that might be too expensive; would LNCS prices be reasonable in current market conditions? We use pricing software of an investment bank $^{1}$ and real market data ${ }^{2}$ to compute LNCS prices using a Heath-Jarrow-Morton (HJM) two-factor model (see Heath et al. (1992)) for interest rates and a (micro-macro) population dynamics model described in Bensusan (2010) in order to obtain extreme nominal structures for a real insurance portfolio. The HJM two-factor model is widely used by banks. It may underestimate uncertainty of interest rates for long-term risks, but it takes into account correlation of interest rates that plays an important role for this kind of product.

Our results show that it would be currently affordable and interesting for insurance companies to use this kind of instrument. However, as interest rates are now quite low and as the LNCS

\footnotetext{
${ }^{1}$ We are highly indebted to the team of Interest rates Modeling of CACIB.

${ }^{2}$ Thanks to the French institute INSEE
} 
provides protection against low interest rates, LNCS prices could be much higher in a market with high interest rates, because the risk that interest rate decrease would be more important. Besides, pension funds hope that interest rates will soon increase after the end of intervention of central banks, which could limit the influence of biometric risks. But this may take some time and is likely to happen together with inflation. Consequently the impact might vary a lot from one stakeholder to the other: part of the pensions are indexed on some inflation index (which has recently changed in the United Kingdom), while some others are not (even in the same pension fund, we might face both types of liabilities). For many insurers, pensions are not necessarily indexed on inflation, but benefit from some profit sharing mechanism (revaluation of pensions). In all cases, there might be adverse scenarios for pension providers which correspond to particular movements of interest rates, inflation rate, and real interest rate (interest rate minus inflation). For life insurers and reinsurers, risk analysis must be global, because a sharp rise of interest rates could have severe consequences on savings contracts. For large insurance groups offering non-life insurance in addition, inflation could arise some issues as well because costs would then be likely to increase faster than expected. In this paper, for simplicity we do not take inflation and profit sharing into account. We believe that for a large part of inflation and interest rate risks, our reasoning could in practice be adapted to the risk profile of the pension provider. The strategy could involve different products, similar to LNCS, but with inflation or real interest rate components. The prices could of course be much higher (or lower), and it could be more difficult to find liquid hedging instruments in some particular cases.

The paper is organized as follows. In Section 2, we recall financial concepts related to swaps and swaptions on interest rates. In Section 3, we describe LNCS cash-flows structure. Section 4 deals with the interest rate and longevity risks models. In Section 5, we carry out a quantitative analysis of the product on real data. We finally give directions for further research in the conclusion.

\section{Traditional Interest Rate Risk Transfer}

\subsection{Plain Vanilla Swap Contract}

A plain vanilla swap contract is an agreement on the OTC market between two parties to exchange, on specific dates, fixed-rate interest on a notional principal for a floating-rate interest rate on the same notional. Initially, both legs should have the same value, otherwise it would not be a fair deal, therefore swap contracts have a zero initial market value. Later on, prices can differ depending on the evolution of the yield curve. For a given maturity, the market quote convention consists for the swap market maker in setting the floating leg at LIBOR, and then quoting the fixed rate, called the swap rate, that makes the value of the swap equal to 
zero. Swaps can be used to optimize the financial condition of the debt, or to hedge a portfolio of fixed-income securities against any change in the yield curve. The OTC swap market is a very liquid market. Different types of contracts may be negotiated, for instance inflation-linked swaps.

In the precise definition of a plain vanilla swap, there are given a nominal amount $N$, a floating LIBOR rates (with tenor $\delta$, in general 3 or 6 months) and a pre-specified collection of reset/settlement dates, $[\mathbf{T}]=\left[T_{1}, \cdots, T_{n}\right]$ referred to as the tenor structure and a starting time $T_{0}<T_{1}$. The year fraction between any two consecutive dates is denoted by $\delta_{j}=T_{j}-T_{j-1}$ and is in general constant and equal to the tenor $\delta$ of the LIBOR rates. The value of the LIBOR floating rate at time $T_{i}$ is denoted $L\left(T_{i}, \delta\right)$, but in a plain vanilla swap, the reference floating rate is the one known at the previous date, so that the coupon paid in $T_{i}$ is $\delta L\left(T_{i-1}, \delta\right) \times N$. The cash flows associated with the floating leg of the plain vanilla swap define also a cash flows term structure $\left[\mathbf{C}^{\text {flex }}\right]=\left[N \delta L\left(T_{0}, \delta\right), N \delta L\left(T_{1}, \delta\right), \cdots, N \delta L\left(T_{n-1}, \delta\right)\right]$.

The floating leg of a swap with a one payment date is the interest paid at the end of a loan with tenor $\delta$ and nominal 1 . Then the present value at $T_{0}$ of $1+\delta L\left(T_{0}, \delta\right)$ paid in $T_{0}+\delta$ is 1 , and the one of the floating leg is $\operatorname{FLL}\left(T_{0}, T_{0}, T_{0}, \delta\right)=1-B\left(T_{0}, T_{0}+\delta\right)$, where $B(t, T)$ is the price at $t$ of a zero-coupon bond maturing at $T$. At any date $t<T$, the present value becomes $\operatorname{FLL}\left(t, T_{0}, T_{0}, \delta\right)=B\left(t, T_{0}\right)-B\left(t, T_{0}+\delta\right)$. Using the forward price of the zero-coupons bond $B_{t}\left(T_{0}, T_{0}+\delta\right)=B(t, T+\theta) / B(t, T)$, the forward price $\mathrm{FLL}_{t}\left(T_{0}, \delta\right)$, that is the price at $t$ for a floating leg starting at $T_{0}$, is $1-B_{t}\left(T_{0}, T_{0}+\delta\right)$.

For a general floating leg, the cash flows are still similar to the interests of a loan with variable interest rate written on a nominal amount $N$; and since the present value of the loan at any settlement dates is equal to the nominal (at par) at any payment date in terms of zerocoupon bond $\mathrm{B}(\mathrm{t}, \mathrm{T})$, we obtain easily the value of the floating leg as $\operatorname{FLL}\left(T_{0}, T_{0},[\mathbf{T}], \delta\right)=$ $N\left(1-B\left(T_{0}, T_{n}\right)\right)$. Then the value at time $t<T_{0}$ is $\operatorname{FLL}\left(t, T_{0},[\mathbf{T}], \delta\right)=N\left(B\left(t, T_{0}\right)-B\left(t, T_{n}\right)\right)$ and the forward value $\mathrm{FLL}_{t}\left(T_{0},[\mathbf{T}], \delta\right)=N\left(1-B_{t}\left(T_{0}, T_{n}\right)\right)$.

The value of the fixed leg $\operatorname{FIL}\left(t, T_{0},[\mathbf{T}], \delta\right)$ for a given swap rate $S\left(t, T_{0},[\mathbf{T}], \delta\right)$ is the sum of the discounted future cash flows, $\operatorname{FIL}\left(t, T_{0},[\mathbf{T}], \delta\right)=N S\left(t, T_{0},[\mathbf{T}], \delta\right) \sum_{i=1}^{n} \delta B\left(t, T_{i}\right)$. By equating both values, it follows that,

$$
S\left(t, T_{0},[\mathbf{T}], \delta\right)=\frac{B\left(t, T_{0}\right)-B\left(t, T_{n}\right)}{\sum_{i=1}^{n} \delta B\left(t, T_{i}\right)}=\frac{1-B_{t}\left(T_{0}, T_{n}\right)}{\sum_{i=1}^{n} \delta B_{t}\left(T_{0}, T_{i}\right)} .
$$

The swap rate with forward start, and the forward swap rate are the same: $S\left(t, T_{0},[\mathbf{T}], \delta\right)=$ $S_{t}\left(T_{0},[\mathbf{T}], \delta\right)$.

When the swap contract is more exotic, for example with a given decreasing nominal term structure $[\mathbf{N}]=\left[N_{1}, N_{2}, \cdots, N_{N}\right],\left(N_{1} \geq N_{2} \cdots \geq N_{n}\right)$ the valuation of the floating leg may be made by different methods. The simplest and well-suited for hedging purpose is to use a family of plain vanilla swaps with different nominal and tenor structure, $\left(\left[\mathbf{T}_{\mathbf{n}}\right]=\left[T_{1}, \cdots, T_{n}\right],\left[\mathbf{N}_{\mathbf{n}}\right]=\right.$ 
$\left.\left[N_{n}, \cdots, N_{n}\right]\right),\left(\left[\mathbf{T}_{\mathbf{n}-\mathbf{1}}\right]=\left[T_{1}, \cdots, T_{n-1}\right],\left[\mathbf{N}_{\mathbf{n}-\mathbf{1}}-\mathbf{N}_{\mathbf{n}}\right]=\left[N_{n-1}-N_{n}, N_{n-1}-N_{n}, \cdots, N_{n-1}-\right.\right.$ $\left.N_{n}\right]$ ) and so on to the latter $\left(T_{1}, N_{1}-N_{2}\right)$, whose the sum replicated exactly the cash flows of the flex leg of the exotic swap. The present value of the floating leg is, with the convention $N_{n+1}=0, \operatorname{FLL}\left(t, T_{0},[\mathbf{T}],[\mathbf{N}]\right)=\sum_{i=1}^{n}\left(N_{i}-N_{i+1}\right)\left(B\left(t, T_{0}\right)-B\left(t, T_{i}\right)\right)$. By equating fix and floating legs at time $t$, we fix the swap rate of the exotic swap,

$$
\delta S\left(t, T_{0},[\mathbf{T}],[\mathbf{N}], \delta\right)=\frac{\sum_{i=1}^{n}\left(N_{i}-N_{i+1}\right)\left(B\left(t, T_{0}\right)-B\left(t, T_{i}\right)\right)}{\sum_{i=1}^{n} N_{i} B\left(t, T_{i}\right)}
$$

Example We start with a path of the LIBOR rate corresponding to a decline of interest rates between years 2009 and 2012, and a sharp rise between 2012 et 2020. This type of scenario will have a strong impact on the floating leg of the exotic swap, whose nominal term structure has been estimated using our mortality model described in Section 4.
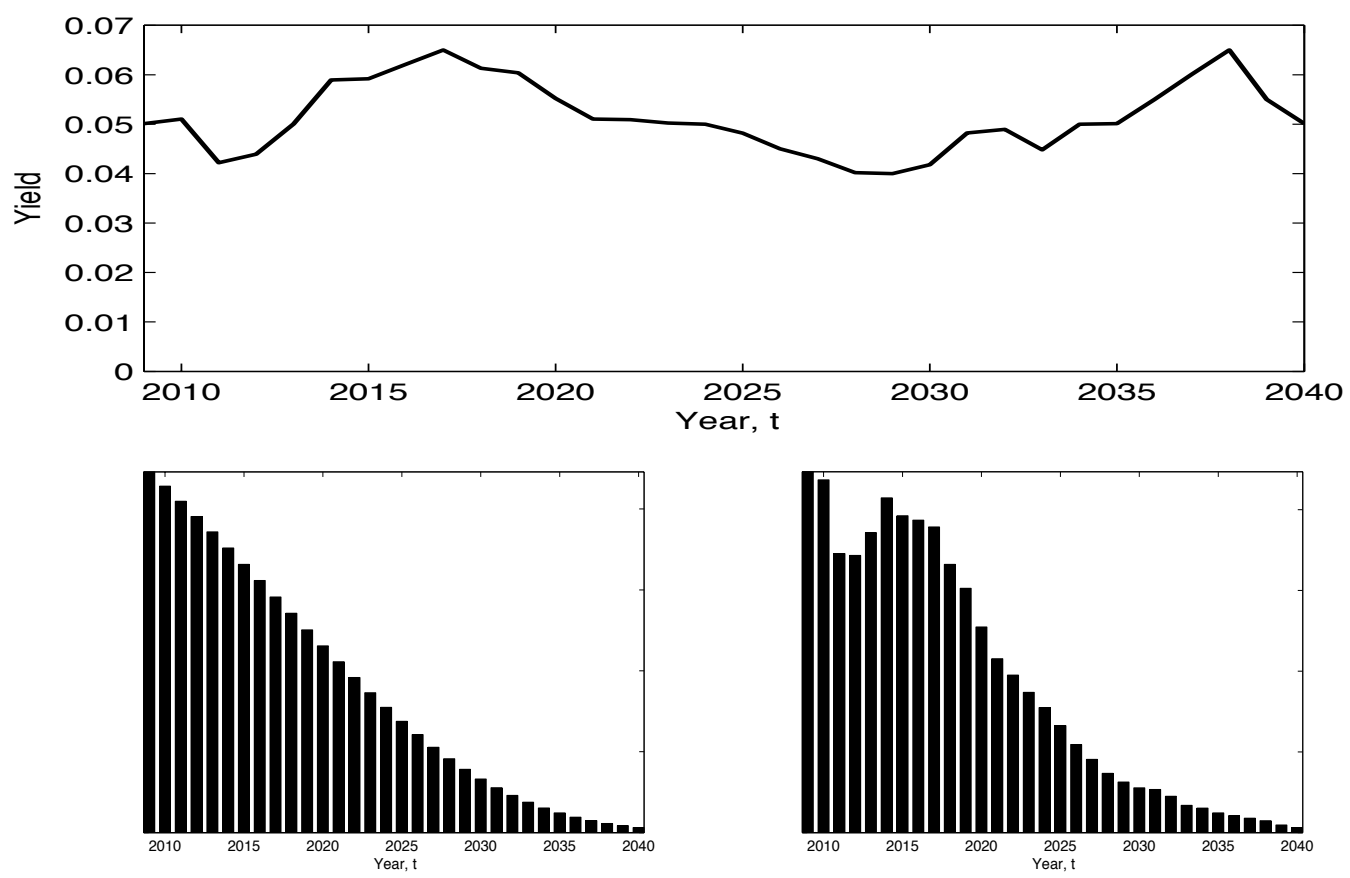

Figure 1: Top panel: Simulated path of the LIBOR rate $\delta L(t, \delta)$ between 2009 and 2040. Bottom panel: Cash flows of the fixed leg of swap with nominal term structure: $\delta k N_{t}$ (left) and cash flows of the floating- leg of swap with nominal term structure: $\delta L(t, \delta) N_{t}$ (right).

\subsection{Swaptions}

A European swaption is an option allowing the holder to enter into some pre-specified underlying swap contract, on a pre-specified date, which is the expiration date of the swaption. There are two kinds of European swaptions: the receiver swaption is an option that gives the buyer the right to receive the fixed leg of the swap, the payer swaption is an option that gives 
to the buyer the right to pay the fixed leg of the swap. The strike rate is the specified fixed rate at which the buyer can enter into the swap. The maturity or expiry date is the date when the option can be exercised. The maturity can range from several months to ten years. The premium of the plain vanilla swaption is expressed as a percentage of the principal amount of the swap.

The pay-off of receiver swaption on a plain vanilla swap, at maturity $T \leq T_{0}$, is the positive part $\sup \left(\Phi_{T}\left(T_{0},[\mathbf{T}], N, K, \delta\right), 0\right)$ of $\Phi_{T}\left(T_{0},[\mathbf{T}], N, K, \delta\right)=\left(K-S_{T}\left(T_{0},[\mathbf{T}], \delta\right)\right) \sum_{i=1}^{n} N \delta B\left(T, T_{i}\right) ;$ using the properties of the floating leg, we also have $\Phi_{T}\left(T_{0},[\mathbf{T}], N, K, \delta\right)=\left(K \sum_{i=1}^{n} N \delta B\left(T, T_{i}\right)-\right.$ $\left.\left(B\left(T, T_{0}\right)-B\left(T, T_{n}\right)\right)\right)$. In other terms, the pay-off is the positive part of the difference of $K$ times the market value of the fixed leg and the market value of the floating leg. The swaption is said to be at the money, when the strike price is closed to the forward swap rate $K \sim S_{t}\left(T, T_{0},[\mathbf{T}], \delta\right)$.

When the swaption has a variable nominal term structure, the pay-off becomes the positive part $\sup \left(\Phi_{T}\left(T_{0},[\mathbf{T}],[\mathbf{N}], K, \delta\right), 0\right)$ of

$$
\Phi_{T}\left(T_{0},[\mathbf{T}],[\mathbf{N}], K, \delta\right)=\left(K \sum_{i=1}^{n} N_{i} \delta B\left(T, T_{i}\right)-\sum_{i=1}^{n} \delta\left(N_{i}-N_{i+1}\right)\left(B\left(T, T_{0}\right)-B\left(T, T_{i}\right)\right)\right) .
$$

Unlike the swap contract whose pricing relies only on the yield curve today, the evaluation of the premium of the swaption contracts requires a dynamic model of interest rates, as the classical HJM two-factor model. When the swap contract has a nominal term structure, the hedging strategy is complex and is based on a basket of vanilla swaptions, whose maturities are adjusted to the tenor structure of the swap.

\section{Longevity Nominal Chooser Swaption: Description and Study}

Let us consider a life-insurer with a large annuity book. She is doubly exposed to longevity risk and financial risks. Longevity risk affects the nominal series and the duration of the future payments, while interest rate risk affects long maturity liabilities (because the insurer must obtain some fixed interest rate to fund them.) If it were possible to know in advance exactly the amount of annuities to be paid to policyholders, the insurer might use swaps or swaptions with (fixed) nominal term structure to reduce her exposure.

But the problem is that, due to longevity risk, nominals are random and depend on the longevity of annuitants. To hedge this risk, the insurer could use longevity swaps (in addition to the swaptions with fixed nominal term structure). However, longevity swaps correspond only to private deals that may be very expensive.

The insurer could prefer to cross-hedge biometric longevity risk with mortality risk. As maturities are in general longer for contracts exposed to longevity risk (30 to 50 years) than for 
contracts exposed to mortality risk (1-10 years), the main residual risk for the insurer would then be interest rate risk associated with those portfolios. If mortality decreases faster than expected, the insurer has to pay less than expected for short-term mortality contracts, but is likely to pay more in the future for her annuity contracts. This increases the nominal amount of the interest rate protection scheme associated to the annuity portfolio.

The proposed LNCS contracts would enable the insurer to re-adjust the nominals of the interest rate coverage after 10 years, say, according to the evolution of longevity improvements observed in this first period.

To help the reader to understand the difference between LNCS contracts and longevity swaps, we recall the main characteristics of longevity swaps in the next subsection before introducing LNCS contracts in more detail.

\subsection{Longevity Swaps}

\subsubsection{Longevity swap transactions and basis risk}

Over the last 4 years, some longevity swap transactions have been completed. They are very private transactions and therefore their pricing remains confidential and subject to negotiation between the various parties involved in the deal. Some of these swaps were contracted between a life insurance company and a reinsurer as a particular reinsurance agreement. Others have involved counterparts outside the insurance industry. Most of these transactions have a very long maturity and incorporate an important counterparty risk, which is difficult to assess given the long term commitment. As a consequence, the legal discussions around these agreements make them particularly heavy to finalize.

Longevity swaps can mainly take two forms, depending on whether they are index-based or customized. We now briefly present two longevity swaps arranged by JP Morgan in 2008. Both are very different in terms of basis risk as detailed below. More precisely,

A customized swap transaction In July 2008, JP Morgan executed a customized longevity swap with a UK life insurer for a notional amount of GBP 500 millions for 40 years. The life insurer has agreed to pay fixed payments and to receive floating payments which replicates the actual payments made on a run-off portfolio of retirement policies. The swap is before all a hedging instrument of cash flows for the life insurer, with no basis risk.

At the same time, JP Morgan entered into smaller swaps with several investors who take longevity risk at the end. In this type of indemnity based transaction, the investors are provided with the relevant information regarding the underlying portfolio for them to be able to assess their risk. The back-to-back swap structure of this transaction means that JP Morgan has no residual longevity exposure. Longevity risk is transferred from the insurer to the investors in return for a risk premium. Counterparty risk for this swap is important given the long term maturity of the transaction, but also the number of agents involved. 
A standardized transaction: Lucida In January 2008, JP Morgan executed a standardized longevity swap with the pension insurer Lucida for a notional amount of GBP 100 millions for 10 years, and using LifeMetrics index for England and Wales as underlying index. This swap structure enables a value hedge for Lucida, which has accepted in this case to keep the basis risk. For more details on both transactions in particular and on longevity swaps, please refer to Barrieu and Albertini (2009).

\subsubsection{Differences between longevity swaps and swaption-type strategies}

In a longevity swap with cash flows occurring each year $1 \leq i \leq p$, the insurer exchanges series of nominals $[\tilde{\mathbf{N}}]=\left[\tilde{N}_{1}, \cdots, \tilde{N}_{p}\right]$ that are random (because of longevity risk associated to her population or to an index) with fixed nominals $[\overline{\mathbf{N}}]=\left[\bar{N}_{1}, \cdots, \bar{N}_{p}\right]$. Each $\bar{N}_{i}$ is equal to the mathematical expectation of $\tilde{N}_{i}$ (under the historical probability measure) plus some risk margin $\rho_{i}>0$. The bank and the insurer have to agree on the values of the $\bar{N}_{i}$ 's at the beginning of the contract, which is often complicated. The risk margin takes into account longevity risk transfer reward, as well as the interest rate risk associated with the cash-flow $\tilde{N}_{i}-\bar{N}_{i}$. Part of this risk margin might be replaced with an upfront payment from the insurer to the hedge provider. In addition to counterparty risk and/or basis risk (depending on the type of longevity swap), the insurer who purchases longevity swap remains with the interest rate risk associated to deterministic cash flows $[\overline{\mathbf{N}}]=\left[\bar{N}_{1}, \cdots, \bar{N}_{p}\right]$, and might use swaps or swaptions to hedge it. It is also possible to define forward-start or deferred longevity swaps, for which cash-flows start after some lag. For example, for portfolios of 50-year-old policyholders, it would be interesting to start exchanging payments after a lag of 10 to 15 years, because pensions would be paid after retirement only.

However, as mentioned before, instead of using longevity swaps (or deferred longevity swaps) and some traditional interest rate coverage, due to heavy costs and due to cross-hedging possibilities with mortality risk, the insurer might prefer to manage longevity risk and to only transfer interest rate risk associated with her annuity portfolio to financial markets. The insurer would then be interested in some interest rate hedging solution for random nominals. We now introduce some new contract that enables such an insurer to re-adjust the nominal series after some time according to her new anticipation of future longevity improvements for her population of annuitants.

\subsection{Description of the Longevity Nominal Chooser Swaption}

Products like swaptions would allow the insurer to hedge dynamically her interest rate risk if there were no longevity risk. We introduce now a new product that enables the insurer to propose some series of nominals at the beginning and to choose the most suitable one after some lag. 
Insurer's point of view Due to longevity risk, it is impossible to know initially, at time $T_{0}$, the level of future nominals. However, the insurer may estimate (at time $T_{0}$ ) two nominal term structures (quantile estimated) starting at time $T>T_{0},\left[\mathbf{N}_{\mathbf{T}}^{+}\right]=\left[N_{1, T}^{+}, N_{2, T}^{+}, \cdots, N_{n, T}^{+}\right]$and $\left[\mathbf{N}_{\mathbf{T}}^{-}\right]=\left[N_{1, T}^{-}, N_{2, T}^{-}, \cdots, N_{n, T}^{-}\right]\left(N_{i, T}^{-}<N_{i, T}^{+}\right)$, in such a way that for each time, the probability that the realized cashflow is between the two corresponding extreme levels is larger than a given level, $95 \%$ for instance. Given that the forecasts are made at time $T_{0}$, our proposed LNCS contract gives the insurer the right to re-adjust her forecasts at time $T$, by choosing (at time $T$ ) a new nominal term structure, convex combination (with parameter $\alpha_{T} \in[0,1]$ ) of the two extreme structures (that had previously been estimated at time $T_{0}$ ),

$$
\left[\mathbf{N}_{\mathbf{T}}^{\alpha}\right]=\alpha_{T}\left[\mathbf{N}_{\mathbf{T}}^{-}\right]+\left(1-\alpha_{T}\right)\left[\mathbf{N}_{\mathbf{T}}^{+}\right]=\left[\mathbf{N}_{\mathbf{T}}^{+}\right]-\alpha_{T}\left[\boldsymbol{\Delta} \mathbf{N}_{\mathbf{T}}\right]
$$

where $\left[\boldsymbol{\Delta} \mathbf{N}_{\mathbf{T}}\right]=\left[\mathbf{N}_{\mathbf{T}}^{+}\right]-\left[\mathbf{N}_{\mathbf{T}}^{-}\right]$. The parameter $\alpha_{T}$ is chosen by the insurer at time $T$, depending on the actual annuity portfolio and the new estimate at time $T$ of the future nominal term structure. This has motivated the choice of the name of the product, Longevity Nominal Chooser Swaption. To recap, the insurer wishes to transform her fixed annuity rate $k$ into a floating rate, by contracting a receiver swaption: she pays the floating rate and receives fixed rate (swap rate) on the appropriate nominal. She is waiting for a fixed rate close to the annuity rate; this can be obtained by adding a spread or margin $m$ at the floating rate (because capital is consumed), and by fixing the strike $K$ of the swaption very close to $(k-m)$, which corresponds to the notion of technical interest rate for the insurance company. For instance, when the floating rate is fluctuating around $2.1 \%$ and the annuity rate around $4 \%$ the margin will be $1.9 \%$.

Seller's point of view From the seller's point of view, the contract is priced on the basis of the worst scenario, corresponding to the maximum of the payoffs, that is the maximum of the positive part of the family of random variables $\Phi_{T}\left(T_{0},[\mathbf{T}],\left[\mathbf{N}_{\mathbf{T}}^{\alpha}\right], \mathbf{K}, \delta\right)=\mathbf{\Phi}_{\mathbf{T}}\left(\mathbf{T}_{\mathbf{0}},[\mathbf{T}],\left[\mathbf{N}_{\mathbf{T}}^{+}\right], \mathbf{K}, \delta\right)-$ $\alpha_{\mathbf{T}} \boldsymbol{\Phi}_{\mathbf{T}}\left(\mathbf{T}_{\mathbf{0}},[\mathbf{T}],\left[\boldsymbol{\Delta} \mathbf{N}_{\mathbf{T}}\right], \mathbf{K}, \delta\right)$, where $\Phi_{T}\left(T_{0},[\mathbf{T}],\left[\mathbf{N}_{\mathbf{T}}\right], \mathbf{K}, \delta\right)$ is defined in Equation (2.3). Thanks to this affine representation, the maximum is reached when $\Phi_{T}\left(T_{0},[\mathbf{T}],\left[\boldsymbol{\Delta} \mathbf{N}_{\mathbf{T}}\right], \mathbf{K}, \delta\right)$ is negative, and $\alpha_{T}^{*}$ is the indicator function of the set $\left\{\Phi_{T}\left(T_{0},[\mathbf{T}],\left[\boldsymbol{\Delta} \mathbf{N}_{\mathbf{T}}\right], \mathbf{K}, \delta\right)<\mathbf{0}\right\}$. Then, an easy calculation yields to the maximum underlying pay-off, (where we omit the symbol $\delta$ to simplify the writing)

$$
\Phi_{T}\left(T_{0},[\mathbf{T}],\left[\mathbf{N}^{\alpha_{\mathbf{T}}^{*}}\right], \mathbf{K}\right)^{+}=\left\{\begin{array}{c}
\Phi_{T}\left(T_{0},[\mathbf{T}],\left[\mathbf{N}_{\mathbf{T}}^{+}\right], \mathbf{K}\right)^{+} \text {if } \mathbf{\Phi}_{\mathbf{T}}\left(\mathbf{T}_{\mathbf{0}},[\mathbf{T}],\left[\boldsymbol{\Delta} \mathbf{N}_{\mathbf{T}}\right], \mathbf{K}\right) \geq \mathbf{0} \\
\Phi_{T}\left(T_{0},[\mathbf{T}]\left[\mathbf{N}_{\mathbf{T}}^{-}\right], \mathbf{K}\right)^{+} \text {if } \mathbf{\Phi}_{\mathbf{T}}\left(\mathbf{T}_{\mathbf{0}},[\mathbf{T}],\left[\boldsymbol{\Delta} \mathbf{N}_{\mathbf{T}}\right], \mathbf{K}\right)<\mathbf{0}
\end{array}\right.
$$




\subsection{Practical Aspects}

Of course, contrary to customized longevity swaps, LNCS contracts only offer protection against interest rate risk, but not against biometric longevity risk that must be managed by the insurer. However the insurer knows exactly what is covered and can adapt the interest rate protection to her specific longevity risk profile.

Although it requires a specific "design" because of two curves of future nominal, it better suits to the real problems of the insurer. In this structured product, the only longevity risk supported by the seller (the bank) concerns the maturity of the underlying swap, since the more expensive scenario is easily identifiable. Then, the Longevity Nominal Chooser Swaption is a pure interest rate exotic product, whose hedging instruments are swaptions of different maturities, and different strikes. Maturity $T_{n}$ must reflect the time at which all policyholders have died, or more realistically the time at which the number of policyholders still alive is smaller than some threshold: after this date, the cost of the residual annuities is very low.

Regarding pricing and hedging of this exotic swaption, the seller can rely on a model of interest rates, as in Section 4, rich enough to provide sufficiently significant correlations between long maturity interest rates.

It is not compulsory to consider convex combinations of the two extreme series of nominals. In our example, this was satisfactory, but it may happen that it is better to consider instead quantile curves of regular levels $(5 \%, 10 \%, 15 \%, \ldots, 95 \%)$. This could be important when the quantile curve of level $50 \%$ is quite different from the one obtained with the half sum of extreme levels. Finally, to estimate the extreme curves of policyholder survivor, the insurer has to reduce basis risk, reflecting the selection bias between policyholders and the general population. We suggest to use the micro-macro framework, recently introduced in Bensusan (2010) (see also Barrieu et al. (2012)).

\section{Modeling Longevity and Interest Rate Risks}

Longevity basis risk is strongly present in longevity swap contracts, because longevity exposure is usually based on national population demographic behavior that may significantly differ from the one of policyholders. It often relates to mismatches in demographic characteristics of both populations, as gender, age, socioeconomic classes, geographic location. For the LNCS, and more generally from a modeling perspective, longevity basis risk comes from the difference between the calibration data and the mortality rates specific to the insured population. The following model is a way to reduce basis risk. 


\subsection{Dynamic Individual Mortality Model}

All classical models are referring to the same mortality indicators, as:

(i) the survival probability function $S_{t, a}(T)$, at date $t$ for an individual aged $a$, defined as the probability $S_{t, a}(T)=\mathbb{P}\left(\tau_{a}>T \mid \tau_{a}>t\right)$, where $\tau_{a}$ is the death time and the mortality force (intensity) at time $t$,

(ii) the mortality force (intensity) at time $t, \mu(a, t)=-\partial_{T} \log S_{t, a}(T)$.

(iii) the one-year death probability $(q(a, t))$ depending on calendar year and age.

Indeed, in practice, we can only estimate the discrete mortality on an annual basis. The challenge is to model simultaneously the dynamics of all mortality rates, $(q(a, t))_{a, t}$.

Classical stochastic mortality models Many stochastic mortality models have been developed recently by Lee and Carter (1992), Lee and Miller (2001), Cairns et al. (2006, 2007) among others. Based on the observed linear behavior (at least for the 40-90 age range) of the $\operatorname{logit}^{3}$ transform of the yearly death rate $(q(a, t))$, Cairns et al. (2006) propose a simple yet robust methodology for projecting mortality featuring both age $a$ and period effect $t$ for long time horizon with a reasonable confidence interval. A particular example is the CDB model well-suited to our problem, featuring both the cohort effect and the age-period effect. It is is a regression model, of type

$$
\operatorname{logit} q(a, t)=\alpha_{1}(t)+a \alpha_{2}(t)+\varepsilon(a, t), \quad \varepsilon(a, t) \sim \mathcal{N}\left(0, \sigma(t)^{2}\right)
$$

A model is necessary to specify the time behavior of estimated parameters $\alpha(t)=\left(\alpha_{1}(t) \alpha_{2}(t)\right)^{T}$, viewed for instance as the realization of two-dimensional autoregressive process, as

$$
\alpha(t+1)=\alpha(t)+\mu+C Z(t+1)
$$

where $\mu$ is a $2 \times 1$ constant vector, $C$ is a $2 \times 2$ lower triangular matrix and $Z(t+1)$ is a two-dimensional standard normal variable.

This model can be extended to take into account the cohort effect (as in Cairns et al. (2007)) by adding a new component $\gamma(t-a)$. To take also into account the catastrophic behavior due to some exogenous events impacting the mortality, e.g. flu pandemics, heat waves, and other relevant catastrophic factors, we can add a jump component $B_{t} E_{t}$ where $B_{t}$ is a Bernoulli distributed variable with parameter $p$ and $E_{t}$ is an exponentially distributed variable with parameter $\lambda$.

To capture basis risk, we enrich the two-factor model by integrating some additional individual characteristics, also called traits in the sequel (among others, gender, socioeconomic status, education level and matrimonial status, and also global factors as geographical loca-

\footnotetext{
${ }^{3}$ The logit function is defined as: $\operatorname{logit}(x)=\log \frac{x}{1-x}$
} 
tion, country, and environmental factors). These factors affect some homogeneous age classes $\mathcal{A}=\left\{A_{l}, 1 \leq l \leq N\right\}$. All these new variables take finite qualitative or quantitative values $x=\left(x_{i}\right)_{1 \leq i \leq M_{x}}$.

We henceforth denote by $q(a, t, x)$ the one-year death probability under the new specification, which is given by the following equation:

$$
\operatorname{logit}(q(a, t, x))=\alpha_{1}(t)+a \alpha_{2}(t)+\gamma(t-a)+\sum_{i=1}^{M_{x}} \beta_{i}^{l}(t)^{\top} x_{i}+B_{t} E_{t}+\varepsilon(a, t, x, y)
$$

Here, $\left(\beta_{i}^{l}\right)_{1 \leq i, l \leq M_{x}, N}$ are the coefficients of the logistic regression over specific one-year death probabilities.

Dynamic micro-macro stochastic longevity models In the previous models for mortality, the variance of the mortality process exponentially grows in time, leading to inaccurate long-term estimations. In order to assess the future patterns of the survival function of annuitant portfolio, we propose a microscopic approach taking into consideration the age and the characteristics (or traits) of each individual in the portfolio. The model may be adapted to include some epidemiological considerations. We are inspired from stochastic models for age-structured population with variable traits used in biology as in Ferrière and Tran (2009); detailed explanations may be found in the PhD thesis of Bensusan (2010).

As in the CDB model, we consider that the annuitants share some global traits that evolve during their lifetime with a rate depending on their age, and others parameters, influencing their yearly death probability.

Starting with an annuitant portfolio of $N_{0}$ individuals, our goal is to derive future evolution of the individuals still alive at each time; we simulate by recursion a succession of events occurring at random dates $\left(T_{k}\right)$ and modifying the size and the characteristics of the population. At time $\left(T_{k}\right)$, the size of the population is $N_{T_{k}}$. The latter events are simulated using a sequence $\left(\tau_{k, \ell}\right)$ of possible event dates following a Poisson point process with an intensity depending on the size of the population and on the threshold death probability $\lambda\left(N_{T_{k}}, T_{k}\right)$. On the time interval $\left[\tau_{k, \ell}, \tau_{k, \ell+1}\right)$, only aging occurs. We assimilate the population to a box denoted $\operatorname{Box}_{\left(T_{k}+\tau_{k, \ell+1}\right)-}$ that initially contains $N_{T_{k}}$ individuals, characterized by their traits at time $T_{k}$ and their age at time $T_{k}+\tau_{k, \ell+1}$. Choosing randomly an individual in the box, we simulate its future state (still alive, dead, with new traits) given the probability of this evolution calibrated in the CDB model. When nothing happens, we reiterate the algorithm until we obtain the $k+1^{\text {th }}$ event, and then generate a new box called $\operatorname{Box}_{T_{k+1}}$, with either one person missing or some change in the traits for one individual. That is, if the number of individuals is high we might inspect the box more often, and changes occur due to death or changes on the characteristic of the individual.

Given its flexibility, the model may be adapted to more complex situations. Since it is par- 
simonious in the exploration of individuals evolution, it is efficient for long term simulations, and gives information on the proportion of individuals with different characteristics still alive at the horizon of the simulation. Moreover, it provides an easy way to estimate future annuity cash-flows, and to generate stress tests.

\subsection{Modeling Interest Rates via HJM Two-Factor Models}

A major milestone in interest modeling was the one-factor Gaussian mean reverting model proposed by Vasicek (1977) for the short-term interest rate, using a time-homogeneous set-up of the Ornstein-Uhlenbeck process. Its tractability and numerical efficiency made the model popular among practitioners for many years. The extension to time dependent parameters to

fit the yield curve or to bi-dimensional Gaussian case is straightforward. It is motivated by the impact of the slope of the yields curve on the pricing of exotic swaptions. Based on the instantaneous correlation of the Gaussian factors, this two-dimensional extension leads to non trivial correlation between two forward rate with successive maturities. For more details on the model, see Rebonato (1998), or Acar and Natcheva-Acar (2009).

Formally, given the yield curve today and the HJM framework, the yield curve dynamics is determined by the term structure of the volatility of spot forward rates $f(t, T)=-\partial_{T} B(t, T)$ where $B(t, T)$ is the zero-coupon bond maturing in $T$, given that

$$
d f(t, T)=\mu(t, T) d t-\gamma(t, T) d W_{t}^{\top}, \quad \mu(t, T)=\gamma(t, T)^{\top} \int_{t}^{T} \gamma(t, s) d s,
$$

where $W$ is a two-dimensional Brownian motion on the risk neutral probability $\mathbb{Q}$. A classical choice for the volatility vector is as follows, where $a(t), b(t)$ and $\theta(t)$ are deterministic real functions:

$$
\gamma(t, T)=a(t) b(T)\left(\begin{array}{c}
\cos \theta(t) \\
\sin \theta(t)
\end{array}\right)
$$

Function $a$ defines the volatility level, while function $b$ is useful when modeling forward volatility. Moreover the correlation between two forward rates with successive maturities denoted by $\rho_{i}$, for $i=1, \cdots, N$, is given by $\operatorname{cor}\left(f\left(., T_{i}\right), f\left(., T_{i+1}\right)\right)=\cos \left(\theta\left(T_{i+1}\right)-\theta\left(T_{i}\right)\right)$. The function $\theta$ is the first function to calibrate on historical market data.

\section{Quantitative Analysis}

To settle a LNCS coverage, we must distinguish two key steps. At the starting date of the contract, the insurer determines upper and lower scenarios of the nominals, i.e. $\left[\mathbf{N}_{\mathbf{T}}^{+}\right]$and $\left[\mathbf{N}_{\mathbf{T}}^{-}\right]$, of her annuitant portfolio. This step is critical to ensure the effectiveness of the interest rate hedge by forecasting as accurately as possible the evolution of annuitant survival curve. 
Using the model previously introduced allows us to develop a refined projection of mortality by leveraging all available information at individual level. In practice, we cannot calibrate such a model directly on the insurer dataset, because it is far too small. We would first use national detailed mortality data like the échantillon démographique permanent provided by INSEE in France in order to calibrate the proposed longevity model that takes traits into account. Then, the insurer would use this model to determine quantiles of cash-flow nominals for her population of policyholders, using their current observed real traits of the annuitants. The nominals are thus intimately dependent on the traits of individuals of a group of individuals that display some degree of heterogeneous mortality. Using this approach, longevity basis risk is strongly reduced. Second, at the first maturity $T$ of the LNCS, the insurer chooses a nominal stream $\left[\mathbf{N}_{\mathbf{T}}^{\alpha}\right]$ among one of the convex combinations of the quantile pre-estimated (at initial time $T_{0}$ ) nominal streams $\left[\mathbf{N}_{\mathbf{T}}^{+}\right]$and $\left[\mathbf{N}_{\mathbf{T}}^{-}\right]$.

In the sequel, we explore a real-world application. Due to the unavailability of a more detailed dataset, the only considered traits are the age and the gender of each individual of a real-world annuitant portfolio. Of course, a real insurer could refine the computation of the extreme nominal series thanks to additional traits that might be available in her dataset. In general, this would not change much our conclusions about how affordable LNCS contracts are in present market conditions, even if prices may vary from one insurer to the other due to basis risk.

\subsection{Description of the Real Insurance Portfolio}

Let us consider a real-world insurance portfolio with 62482 French, male policyholders in 2012, with the age structure shown in Figure 2.

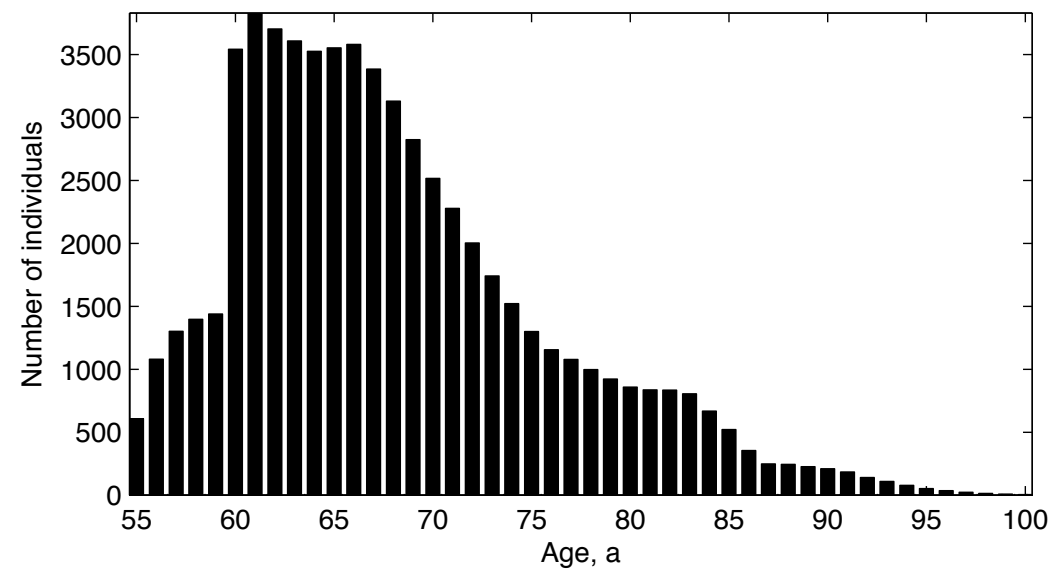

Figure 2: Age structure of policyholders 
The micro-macro approach described in Section 4 with the partial information consisting in ages and genders only, allows us to evaluate the 5\% (dotted line) and 95\% (do-dashed line) quantiles as well as the median (solid line) of the size of the (not discounted) future cash-flows (see Figure 3).

To simplify, each policyholder are assumed to receive 1 euro per period, but it is possible to introduce heterogeneity and to take it into account in the micro-macro model. It is often necessary because rich policyholders are likely to have larger pensions and tend to live longer in average. As nominals can be substantial, it is important for the insurer to manage interest rate risks dynamically.

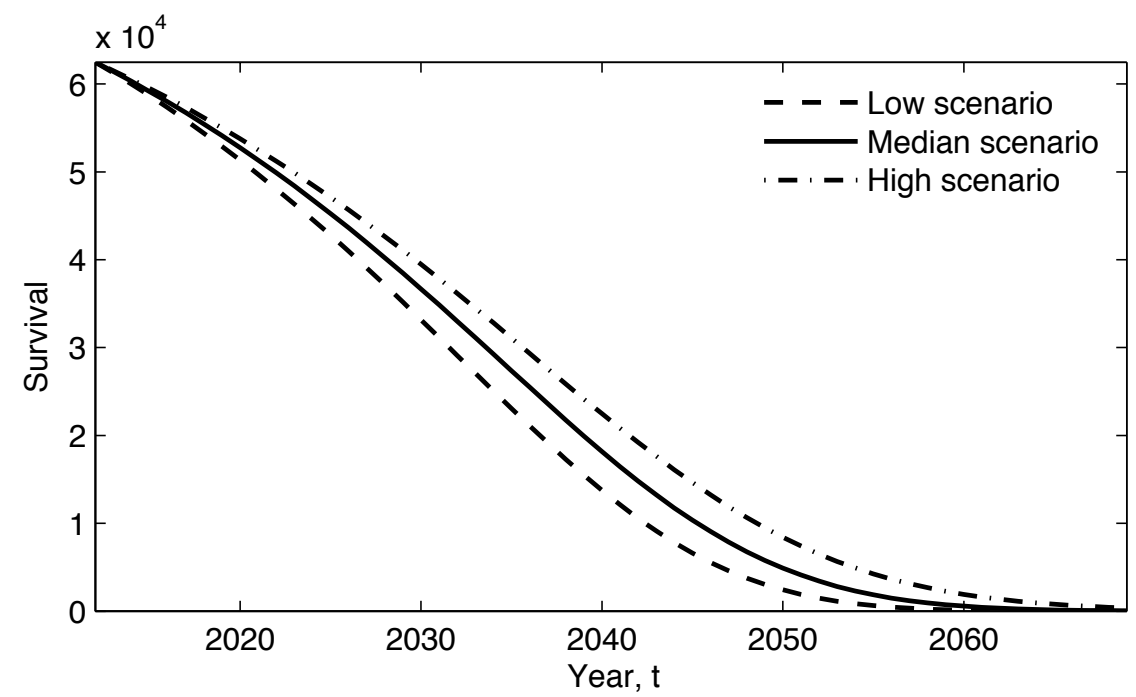

Figure 3: Scenarios of the real-world portfolio evolution

From the micro-macro longevity model, the number of survivors in 10 years is likely to be comprised between 48049 and 51223, with a median equal to 49888. After 10 years, the insurer uses her current information to choose the value of $\alpha_{T}$ such that the nominal term structure corresponds to her updated mortality projections. This can be done in different ways. A first naive method consists in matching the number of survivors in 10 years: as shown in Figure 4, if there were 49000 survivors in 2022, we could choose

$$
\alpha_{T}=\frac{N_{T}^{+}-N_{T}}{N_{T}^{+}-N_{T}^{-}}=\frac{51223-49000}{51223-48049} \sim 0.7 .
$$

We could also use weighted least squares method in order to find the nominal structure that best matches the whole series of cash-flows. 


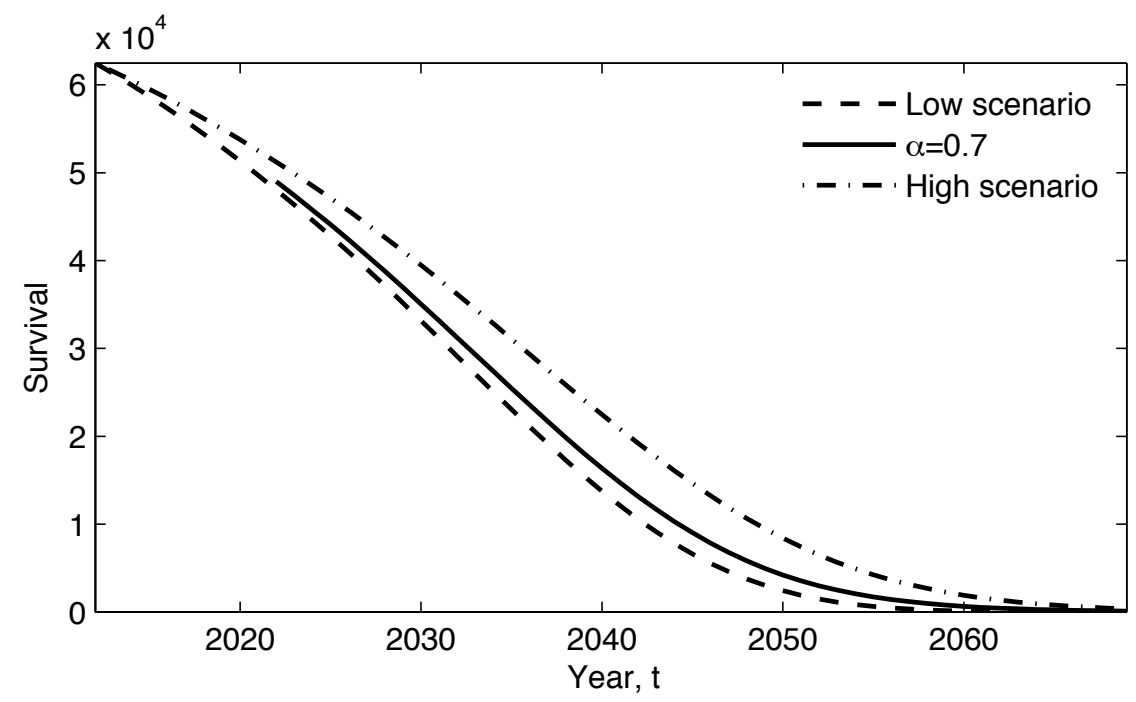

Figure 4: An example of possible choice of the parameter $\alpha_{T}$ in 2022

Alternatively, if the insurer detects a change in longevity trends, she could be interested in more complex nominal structures (than weighted sums of the two extreme ones) to take them into account. Such products would essentially have the same features. However, giving more freedom to the insurer in terms of nominal structure choice could rapidly become expensive and complicated to manage for the bank. The study of such products with more options is left for further research.

\subsection{About the Yield Curve}

An example of yield curve The Euro is the currency used by European insurers whose policyholders are from the Euro zone. We assume that only Euro is involved and we do not introduce exchange rates. The configuration of the European yield curve has varied a lot in the past. We have also studied the impact of reversed curves, or of curves with bumps, but for conciseness we only present results obtained by calibrating the HJM two-factor model on a set of relevant swaption prices and on the European yield curve of January 2nd, 2012 (see Figure 5). This yield curve exhibits a strong difference between short term and long term interest rates, with levels around 2.5\%. This configuration leads to quite high prices because Longevity Nominal Chooser Swaptions provide a hedge against a decrease in interest rates. Recall that in any case, the yield curve gives us the present value of nominal term structure of deterministic cash-flows as

$$
P V_{t}\left([\mathbf{N}]_{\mathbf{T}}\right)=\sum_{i=1}^{p} \mathbf{1}_{\left\{T_{i} \geq t\right\}} N_{T_{i}} B\left(t, T_{i}\right)
$$




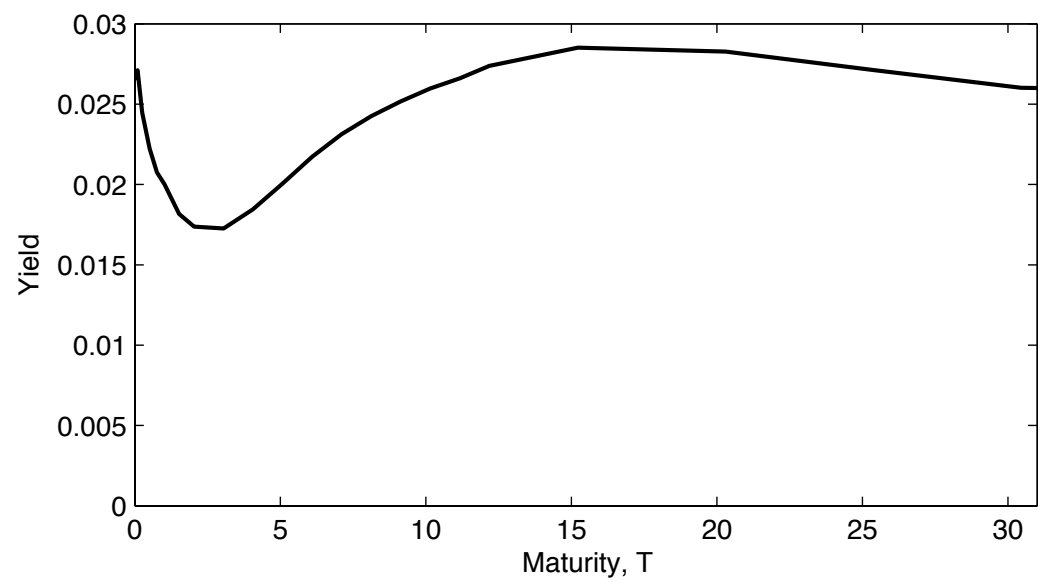

Figure 5: European yield curve of January 2, 2012

Impact of Correlation of Interest Rates As LNCS is an option on maximum, its price is always higher than the one of the most expensive swaption with variable nominal. Besides, the price of the product is strongly dependent with correlations between swap rates for different maturities. These correlations are explained by the one of successive spot forward rates given in Subsection 4.2 by $\rho=\operatorname{cor}(f(., T), f(., T+d t))=\cos (\theta(T+d t)-\theta(T))$. We study the behavior of the product for different values of correlation between swap rates with maturities $10 \mathrm{Y}$ and $12 \mathrm{Y}$, keeping reasonable $\theta$ (low correlation between short and long-term interest rates). The motivation for this choice is given by the average maturity ${ }^{4}$, also called duration, for the lower and upper term structures, equal to $T_{m o y}^{N^{-}}=10 Y$ and $T_{m o y}^{N^{+}}=12 Y$ respectively.

\subsection{Cost on Annuity and Interpretation of Numerical results}

Notion of Cost on Annuity We also assume that the insurer must choose $\alpha$ in $\left\{\frac{l}{10}, 0 \leq l \leq\right.$ $10\}$. Given a yield curve, from Equation (5.1), for any annuity rate $k$, annuity price $\mathrm{PV}_{t}(k, \alpha)$ on nominal term structure $k\left[\mathbf{N}^{\alpha}\right]=k\left(\alpha\left[\mathbf{N}^{-}\right]+(1-\alpha)\left[\mathbf{N}^{+}\right]\right)$is the present value of the future cash-flows, discounted using the yield curve,

$$
\mathrm{PV}_{t}(k, \alpha)=k \mathrm{PV}_{t}\left(\left[\mathbf{N}^{\alpha}\right]\right)=\mathbf{k}\left[\alpha \mathrm{PV}_{\mathbf{t}}\left(\left[\mathbf{N}^{-}\right]\right)+(\mathbf{1}-\alpha) \mathrm{PV}_{\mathbf{t}}\left(\left[\mathbf{N}^{+}\right]\right)\right]
$$

The insurer might choose any $\alpha$. The special case $\alpha=1 / 2$ corresponds to the case where the insurer chooses a more basic interest rate protection, based on central longevity projections. We define $c$ as follows in order to quantify the cost of LNCS contracts proportionally to this reference price:

$$
P_{\text {product }}=c\left[\mathrm{PV}_{t}\left(\frac{1}{2}\left[\mathbf{N}^{-}\right]+\frac{1}{2}\left[\mathbf{N}^{+}\right]\right)\right]
$$

\footnotetext{
${ }^{4}$ For a given term structure $[\mathbf{N}]$, the duration is defined by $T_{m o y}^{N}=\frac{\sum_{i=1}^{N} T_{i} N_{T_{i}}}{\sum_{i=1}^{N} N_{T_{i}}}$.
} 
The value of $c / k$ provides an estimation of the additional proportional cost arising from the purchase of the product in the case where the insurer would not need to exercise the option, and pay $c$ instead of an annuity rate $k$. It is reported in the last column of Tables 1, 2 and 3 .

Note also that if the insurer partly hedges interest rate risk on the basis of average longevity scenarios (case $\alpha=0.5$ ), then the cost would correspond to the one of the set of swaptions associated with $\alpha=0.5$. The extra cost for better protection offered by LNCS products is very reasonable (it represents very often around $10 \%$ or $15 \%$ of the cost of the classical swaption strategy in the current market conditions).

Numerical implementation We study the product for different values of correlation between swap rates with maturities $10 Y$ and $12 Y$.

- Here the prices are given in basis points (bps) by multiplying by a ratio equal to $\frac{10000}{N_{0}} \sim 6.25$

- The annuity rate $k$ is assumed to be equal to $4.5 \%$.

- The series of amounts $N_{T_{i}}$ is given in Appendix A which provides the price of the annuities which is equal to 6528 bps and $\mathrm{PV}_{t}(1, \alpha)=\mathrm{PV}_{t}\left(\left[\mathbf{N}^{\alpha}\right]\right)=\frac{P_{\text {annuity }}}{k}=145065$ bps.

We calculate the swap rate $S V\left(0, T_{0},[\mathbf{N}]\right)$ such that the fixed leg is equal to the funding leg. We obtain $S V\left(0, T_{0},[\mathbf{N}]\right)=2.7 \%$. Then, the new series of amounts is given by $\left[\mathbf{N}^{\prime}\right]=$ $\frac{k}{S V\left(0, T_{0},[\mathbf{N}]\right)}[\mathbf{N}]$ (see Appendix A). Then, we present the price of the product and the cost on annuity given by $c=\frac{P_{\text {product }}}{\mathrm{PV}_{t}\left(\frac{1}{2}\left[\mathbf{N}^{-}\right]+\frac{1}{2}\left[\mathbf{N}^{+}\right]\right)}$.

\begin{tabular}{|c|c|c|c|c|c|}
\hline \multirow{2}{*}{$\begin{array}{c}\text { Correlation swaps } \\
10 Y / 12 Y\end{array}$} & \multicolumn{3}{|c|}{ Price } & \multirow{2}{*}{$\begin{array}{l}\text { Price of } \\
\text { product }\end{array}$} & \multirow{2}{*}{$\begin{array}{l}\text { Cost on } \\
\text { annuity }\end{array}$} \\
\hline & $\alpha=0$ & $\alpha=0.5$ & $\alpha=1$ & & \\
\hline $99.6 \%$ & 1098 bp & $983 \mathrm{bp}$ & $871 \mathrm{bp}$ & $1109 \mathrm{bp}$ & $0.764 \%$ \\
\hline $99.3 \%$ & $1072 \mathrm{bp}$ & $965 \mathrm{bp}$ & $860 \mathrm{bp}$ & $1086 \mathrm{bp}$ & $0.749 \%$ \\
\hline $99 \%$ & $1046 \mathrm{bp}$ & $945 \mathrm{bp}$ & 849 bp & $1066 \mathrm{bp}$ & $0.735 \%$ \\
\hline $98.7 \%$ & $1018 \mathrm{bp}$ & $925 \mathrm{bp}$ & $837 \mathrm{bp}$ & $1043 \mathrm{bp}$ & $0.719 \%$ \\
\hline $98.3 \%$ & $988 \mathrm{bp}$ & $903 \mathrm{bp}$ & $824 \mathrm{bp}$ & 1019 bp & $0.702 \%$ \\
\hline $97.8 \%$ & $957 \mathrm{bp}$ & 879 bp & $809 \mathrm{bp}$ & 994 bp & $0.685 \%$ \\
\hline $97.3 \%$ & $924 \mathrm{bp}$ & 854 bp & $793 \mathrm{bp}$ & $967 \mathrm{bp}$ & $0.667 \%$ \\
\hline
\end{tabular}

Table 1: Evolution of price as a function of correlation between swap rates with maturities $10 Y$ and $12 Y$.

Correlation plays an important role, impacting both marginal prices (for swaptions with fixed $\alpha$ ) and the price of the product. The notion of switch option corresponds to the difference between the price of the product and the one of the most expensive swaption and is useful to quantify the exotic character of the product.

As correlation decreases, the price of each swaption decreases, and so does the difference between the prices of the different swaptions. However, the difference between the price of the 
product and the one of the most expensive swaption strongly increases: the lower the correlation, the more exotic the product. For example, when correlation between swap rates with maturities $10 Y$ and $12 Y$ is $99.6 \%$, the difference between prices of swaptions on extreme nominals $(\alpha=0$ and $\alpha=1$ ) is $1098-871=227$ bps and the price of the switch option is $1109-1098=11$ bps. When correlation between swap rates with maturities $10 Y$ and $12 Y$ is $97.3 \%$, the difference between prices of swaptions on extreme nominals is $924-793=131$ bps while the price of the switch option is $967-924=43 \mathrm{bps}$.

To describe this product as precisely as possible, it seems important to use an interest rate model that incorporates a more relevant structure for the correlation between successive interest rate, like the affine model detailed in Bensusan (2010).

The price difference is not very high for this product and enables the insurer to choose the value of $\alpha$ that suits her best in 10 years. For extreme values of (de)correlation, the additional cost only represents $\frac{6043-5774}{5774}=4.6 \%$ of the most expensive swaption, which can still be interesting for an insurer.

In this first example, the most expensive swaption is always the one associated with $\alpha=0$ (extremely high longevity improvements). Let us see whether the strike price (modified by the spread) may modify this behavior.

Strike Price Impact Based on a technical, flat interest rate (around 2.7\%), the insurer wants to be able to fund future cash-flows with returns of the initial investment. The fact that policyholders die provides the insurer with a spread (around 1.8\%) that enables her to serve the annuity rate (around $4.5 \%$ ) to annuitants. Even if the strike price (corrected by the spread) is supposed to be chosen in such a way that the option is close to be at the money (for corrected strike price close to $2.7 \%$ ), we vary the corrected strike and fix correlation between swap rates with maturities $10 Y$ and $12 Y$ equal to $98.7 \%$. We observe an inversion for corrected strike prices between $0 \%$ and $1 \%$. After $0.8 \%$, the swaption with the upper nominal structure is the most expensive. Below $0.8 \%$, this is the one with the lower nominal structure.

The passage from one situation to the other at level $0.8 \%$ (which is quite far from the at-the-money level 2.7\%) could be explained thanks to the analysis of so-called Longevity Maturity Chooser Swaptions introduced in Bensusan (2010) and the level of the considered yield curve that is close to $0.8 \%$ (see Figure 5), because the duration of cash-flows may vary from 10 year in the $N^{-}$scenario to 12 years in the $N^{+}$scenario.

\section{Conclusion}

We have introduced Longevity Nominal Chooser Swaptions in order to transfer interest rates risk from pension funds and annuity providers to investment banks and more generally to financial markets. The product structure was described in detail and further extension and 


\begin{tabular}{ccccccc}
\hline Correlation swaps & Strike price & \multicolumn{3}{c}{ Price } & Price of & Cost on \\
\cline { 3 - 5 } $\mathbf{1 0 Y / 1 2 Y}$ & (corr. w. spread) & $\boldsymbol{\alpha}=\mathbf{0}$ & $\boldsymbol{\alpha}=\mathbf{0 . 5}$ & $\boldsymbol{\alpha}=\mathbf{1}$ & product & annuity \\
\hline $98.7 \%$ & $0 \%$ & $76 \mathrm{bp}$ & $79 \mathrm{bp}$ & $87 \mathrm{bp}$ & $97 \mathrm{bp}$ & $0.067 \%$ \\
$98.7 \%$ & $1 \%$ & $244 \mathrm{bp}$ & $237 \mathrm{bp}$ & $235 \mathrm{bp}$ & $274 \mathrm{bp}$ & $0.189 \%$ \\
$98.7 \%$ & $2 \%$ & $606 \mathrm{bp}$ & $563 \mathrm{bp}$ & $525 \mathrm{bp}$ & $637 \mathrm{bp}$ & $0.439 \%$ \\
$98.7 \%$ & $3 \%$ & $1225 \mathrm{bp}$ & $1108 \mathrm{bp}$ & $996 \mathrm{bp}$ & $1248 \mathrm{bp}$ & $0.86 \%$ \\
$98.7 \%$ & $4 \%$ & $2102 \mathrm{bp}$ & $1874 \mathrm{bp}$ & $1652 \mathrm{bp}$ & $2114 \mathrm{bp}$ & $1.457 \%$ \\
$98.7 \%$ & $5 \%$ & $3182 \mathrm{bp}$ & $2820 \mathrm{bp}$ & $2462 \mathrm{bp}$ & $3287 \mathrm{bp}$ & $2.197 \%$ \\
$98.7 \%$ & $6 \%$ & $4390 \mathrm{bp}$ & $3883 \mathrm{bp}$ & $3379 \mathrm{bp}$ & $4392 \mathrm{bp}$ & $3.028 \%$ \\
$98.7 \%$ & $7 \%$ & $5666 \mathrm{bp}$ & $5010 \mathrm{bp}$ & $4356 \mathrm{bp}$ & $5666 \mathrm{bp}$ & $3.906 \%$ \\
\hline
\end{tabular}

Table 2: Price of product as a function of strike price

\begin{tabular}{ccccccc}
\hline Correlation swaps & Strike price & \multicolumn{3}{c}{ Price } & Price of & Cost on \\
\cline { 3 - 4 } $\mathbf{1 0 Y / 1 2 Y}$ & (corr. w. spread) & $\boldsymbol{\alpha}=\mathbf{0}$ & $\boldsymbol{\alpha}=\mathbf{0 . 5}$ & $\boldsymbol{\alpha}=\mathbf{1}$ & product & annuity \\
\hline $98.7 \%$ & $0 \%$ & $76 \mathrm{bp}$ & $79 \mathrm{bp}$ & $87 \mathrm{bp}$ & $97 \mathrm{bp}$ & $0.067 \%$ \\
$98.7 \%$ & $0.1 \%$ & $86 \mathrm{bp}$ & $89 \mathrm{bp}$ & $97 \mathrm{bp}$ & $109 \mathrm{bp}$ & $0.075 \%$ \\
$98.7 \%$ & $0.2 \%$ & $98 \mathrm{bp}$ & $101 \mathrm{bp}$ & $108 \mathrm{bp}$ & $122 \mathrm{bp}$ & $0.084 \%$ \\
$98.7 \%$ & $0.3 \%$ & $111 \mathrm{bp}$ & $113 \mathrm{bp}$ & $120 \mathrm{bp}$ & $136 \mathrm{bp}$ & $0.094 \%$ \\
$98.7 \%$ & $0.4 \%$ & $125 \mathrm{bp}$ & $127 \mathrm{bp}$ & $149 \mathrm{bp}$ & $151 \mathrm{bp}$ & $0.104 \%$ \\
$98.7 \%$ & $0.5 \%$ & $141 \mathrm{bp}$ & $141 \mathrm{bp}$ & $157 \mathrm{bp}$ & $168 \mathrm{bp}$ & $0.116 \%$ \\
$98.7 \%$ & $0.6 \%$ & $158 \mathrm{bp}$ & $157 \mathrm{bp}$ & $162 \mathrm{bp}$ & $186 \mathrm{bp}$ & $0.128 \%$ \\
$98.7 \%$ & $0.7 \%$ & $177 \mathrm{bp}$ & $175 \mathrm{bp}$ & $178 \mathrm{bp}$ & $205 \mathrm{bp}$ & $0.142 \%$ \\
$98.7 \%$ & $0.8 \%$ & $197 \mathrm{bp}$ & $194 \mathrm{bp}$ & $196 \mathrm{bp}$ & $226 \mathrm{bp}$ & $0.156 \%$ \\
$98.7 \%$ & $0.9 \%$ & $220 \mathrm{bp}$ & $215 \mathrm{bp}$ & $215 \mathrm{bp}$ & $250 \mathrm{bp}$ & $0.172 \%$ \\
$98.7 \%$ & $1 \%$ & $244 \mathrm{bp}$ & $237 \mathrm{bp}$ & $235 \mathrm{bp}$ & $274 \mathrm{bp}$ & $0.189 \%$ \\
\hline
\end{tabular}

Table 3: Price of product as a function of strike price

enhancement could be considered. Our analysis focused on the interest risk and the quantitative sensitivities of the price with respect to the long-term interest rates correlation and to the strike. In a context where interest rates are low, even if many economists anticipate a rise of interest rates and inflation, it might be interesting for some pension providers to protect themselves against low values of interest rates that would last too long, as our analysis shows that prices seem to be reasonable.

A microscopic modeling approach is used to project future cash flows of the product. We have mainly discussed the heterogeneity arising from the age structure and how such an approach should be efficient when further information about policyholders is available, e.g. marital status, socioeconomic status, ... The fact that annuity amounts may differ among policyholders adds another source of heterogeneity. This could be tackled similarly using the microscopic approach. 
So far, we have supposed that the annuitant portfolio is closed to new entries. In case new policyholders entered the portfolio, mortality models would have to be adapted by assimilating the immigration rate to an entry rate on the portfolio (see Bensusan (2010)). The interest rates follow the HJM two-factor model and the impact of the successive forward rates has been considered. We have shown that the correlation has a high impact on the LNCS prices due to long maturities. More complex models could be used to address this issue, such as models involving stochastic volatilities of interest rates yield curve, e.g. Wishart model.

Various other sources of risk should be taken into account. Indeed, given the specific longrun maturity of the proposed security, we should lay the emphasis on counterparty risk. It should be addressed carefully in view of the last global banking crisis. A possible way to enhance counterparty risk is to post collateral, but this is of course not enough, and counterparty risk remains certainly a big obstacle to some risk transfers in the pension industry, be it for protections against longevity risk, interest rate risk or inflation risk. As mentioned in the introduction, inflation may have different impacts, and the main inflation and interest rate risk drivers must be carefully identified before designing a hedging strategy project. The risk of change in the inflation index used by regulators is also important, because it is quite likely on a long period. Of course, the pension provider could use LNCS contracts to manage financial risks, but she would continue to face all biometric risks. Note also that if longevity started to improve only after 10 years (and had remained steady during the 10 first years), the insurer could not foresee the change in the mortality trend after 10 years, and her re-forecast of future nominal amounts would be inaccurate. However this risk is acceptable for the insurer: longevity risk is a trend risk, and consequently a change in the trend that would start after ten years would not have a huge impact before 20 years from now. Nevertheless, this kind of event is clearly an adverse scenario for which interest rate would not be completely hedged by our proposed product. Moreover, it should be noted that the longevity market is characterized by huge exposed notional amounts. The prices we have investigated so far for LNCS contracts must be regarded as minimal prices that do not take into account liquidity risk.

To conclude, let us mention that in the present paper, we implicitly assumed that longevity risk and economic factors, including interest rates, were independent. This assumption should be relaxed in theory, for several reasons. First, pandemics, if they occur, are likely to cause both mortality catastrophes and economic disruption at the same time, because many economic activities would be impossible or delayed. Second, longevity improvements might be reduced in case of poor economic conditions, because health care budgets would be likely to be cut. Third, future age pyramids and life expectations might have some economic impacts due to retirement funding issues and potential changes in consumption habits. Little is known about correlation between middle-term longevity improvements and interest rates, but this correlation should in principle be taken into account in the pricing of LNCS contracts. Nevertheless, even if their limitations and residual risks have to be assessed carefully, LNCS contracts 
seem to represent an interesting way to split financial and biometric risks between financial institutions and insurers at a currently affordable price.

\section{References}

Acar, S., K. Natcheva-Acar. 2009. A guide on the implementation of the heath-jarrow-morton twofactorgaussain short rate model. Tech. rep., FraunhoferITWM.

Barrieu, P., L. Albertini. 2009. The handbook of insurance-linked securities. Wiley Finance.

Barrieu, P., H. Bensusan, N. El Karoui, C. Hillairet, S. Loisel, C. Ravanelli, Y. Salhi. 2012. Understanding, modelling and managing longevity risk: key issues and main challenges. Scandinavian Actuarial Journal 2012(3) 203-231.

Bensusan, H. 2010. Risques de taux et de longévité: Modélisation dynamique et applications aux produits dérivés et à l'assurance vie. Ph.D. thesis, École Polytechnique.

Biffis, E., D. Blake, L. Pitotti, A. Sun. 2011. The cost of counterparty risk and collateralization in longevity swaps. Working Paper.

Biffis, E., P. Millossovich. 2012. Optimal insurance with counterparty default risk. Working Paper .

Blake, D., A.J.G. Cairns, K. Dowd. 2006. Living with mortality: longevity bonds and other mortalitylinked securities. British Actuarial Journal 12(1) 153-197.

Cairns, A.J.G., D. Blake, K. Dowd. 2006. A Two-factor model for stochastic mortality with parameter uncertainty: Theory and calibration. Journal of Risk and Insurance 73(4) 687-718.

Cairns, A.J.G., D.P. Blake, K. Dowd, G. Coughlan, D. Epstein. 2007. A quantitative comparison of stochastic mortality models using data from England \& Wales and the United States. North American Actuarial Journal 13(4) 1-35.

Ferrière, R., V.C. Tran. 2009. Stochastic and deterministic models for age-structured populations with genetically variable traits. ESAIM: Proceedings .

Heath, D., R. Jarrow, A. Morton. 1992. Bond pricing and the term structure of interest rates: A new methodology for contingent claims valuation. Econometrica 60(1) 77-105.

Lee, R., T. Miller. 2001. Evaluating the performance of the Lee-Carter method for forecasting mortality. Demography 38(4) 537-549.

Lee, R.D., L.R. Carter. 1992. Modeling and forecasting US mortality. Journal of the American Statistical Association 87(419) 659-671.

Loisel, S., X. Milhaud. 2011. From deterministic to stochastic surrender risk models: impact of correlation crises on economic capital. European Journal of Operational Research 214(2) 348357.

Menoncin, F. 2008. The role of longevity bonds in optimal portfolios. Insurance: Mathematics and Economics 42(1) 343-358.

Nguyen, T.L. 2011. Risque financier en assurance, variables annuities et risque long terme. Tech. rep., École Polytechnique. 
Rebonato, R. 1998. Interest-Rate Option Models: Understanding, Analysing and Using Models for Exotic Interest-Rate Options. Wiley Series in Financial Engineering.

Salhi, Y., S. Loisel. 2011. Longevity basis risk modeling: A co-integration based approach. Tech. rep., ISFA, Université Lyon 1.

Vasicek, O. 1977. An equilibrium characterization of the term structure. Journal of financial economics 5(2) $177-188$. 


\section{Appendix}

\section{Appendix A : Evolution of Future Survival}

\begin{tabular}{|c|c|c|c|c|c|c|c|}
\hline Year & $\begin{array}{c}\text { Low } \\
\text { scenario }\end{array}$ & $\begin{array}{l}\text { Median } \\
\text { scenario }\end{array}$ & $\begin{array}{c}\text { High } \\
\text { scenario }\end{array}$ & Year & $\begin{array}{c}\text { Low } \\
\text { scenario }\end{array}$ & $\begin{array}{l}\text { Median } \\
\text { scenario }\end{array}$ & $\begin{array}{c}\text { High } \\
\text { scenario }\end{array}$ \\
\hline 2012 & 62482 & 62482 & 62482 & 2041 & 12124 & 16457 & 20825 \\
\hline 2013 & 61259 & 61414 & 61519 & 2042 & 10553 & 14813 & 19214 \\
\hline 2014 & 59984 & 60304 & 60529 & 2043 & 9136 & 13229 & 17642 \\
\hline 2015 & 58675 & 59150 & 59498 & 2044 & 7826 & 11749 & 16097 \\
\hline 2016 & 57302 & 57961 & 58433 & 2045 & 6629 & 10351 & 14646 \\
\hline 2017 & 55881 & 56723 & 57327 & 2046 & 5546 & 9063 & 13233 \\
\hline 2018 & 54405 & 55444 & 56182 & 2047 & 4608 & 7862 & 11902 \\
\hline 2019 & 52888 & 54120 & 54995 & 2048 & 3767 & 6773 & 10674 \\
\hline 2020 & 51332 & 52755 & 53782 & 2049 & 3040 & 5783 & 9501 \\
\hline 2021 & 49721 & 51343 & 52521 & 2050 & 2435 & 4896 & 8414 \\
\hline 2022 & 48049 & 49888 & 51223 & 2051 & 1910 & 4110 & 7413 \\
\hline 2023 & 46341 & 48388 & 49895 & 2052 & 1483 & 3421 & 6496 \\
\hline 2024 & 44588 & 46841 & 48520 & 2053 & 1132 & 2818 & 5666 \\
\hline 2025 & 42814 & 45251 & 47109 & 2054 & 860 & 2302 & 4938 \\
\hline 2026 & 40951 & 43619 & 45665 & 2055 & 636 & 1865 & 4258 \\
\hline 2027 & 39076 & 41942 & 44170 & 2056 & 465 & 1498 & 3656 \\
\hline 2028 & 37162 & 40223 & 42629 & 2057 & 333 & 1192 & 3134 \\
\hline 2029 & 35176 & 38468 & 41078 & 2058 & 235 & 941 & 2674 \\
\hline 2030 & 33154 & 36678 & 39482 & 2059 & 164 & 737 & 2261 \\
\hline 2031 & 31164 & 34860 & 37850 & 2060 & 112 & 572 & 1911 \\
\hline 2032 & 29126 & 33009 & 36179 & 2061 & 76 & 441 & 1605 \\
\hline 2033 & 27111 & 31145 & 34487 & 2062 & 51 & 337 & 1350 \\
\hline 2034 & 25062 & 29262 & 32820 & 2063 & 33 & 259 & 1132 \\
\hline 2035 & 23074 & 27368 & 31092 & 2064 & 21 & 195 & 945 \\
\hline 2036 & 21112 & 25497 & 29344 & 2065 & 14 & 146 & 788 \\
\hline 2037 & 19171 & 23614 & 27592 & 2066 & 8 & 108 & 658 \\
\hline 2038 & 17295 & 21750 & 25866 & 2067 & 5 & 81 & 540 \\
\hline 2039 & 15485 & 19930 & 24140 & 2068 & 3 & 60 & 446 \\
\hline 2040 & 13752 & 18169 & 22471 & 2069 & 0 & 43 & 367 \\
\hline
\end{tabular}

Table 4: Prospective survivals of the annuitants in the real-world portfolio (in 2012). 


\begin{tabular}{|c|c|c|c|c|c|c|c|}
\hline Year & $\begin{array}{c}\text { Low } \\
\text { scenario }\end{array}$ & $\begin{array}{l}\text { Median } \\
\text { scenario }\end{array}$ & $\begin{array}{c}\text { High } \\
\text { scenario }\end{array}$ & Year & $\begin{array}{c}\text { Low } \\
\text { scenario }\end{array}$ & $\begin{array}{l}\text { Median } \\
\text { scenario }\end{array}$ & $\begin{array}{c}\text { High } \\
\text { scenario }\end{array}$ \\
\hline 2012 & 104137 & 104137 & 104137 & 2041 & 20207 & 27428 & 34708 \\
\hline 2013 & 102098 & 102357 & 102532 & 2042 & 17588 & 24688 & 32023 \\
\hline 2014 & 99973 & 100507 & 100882 & 2043 & 15227 & 22048 & 29403 \\
\hline 2015 & 97792 & 98583 & 99163 & 2044 & 13043 & 19582 & 26828 \\
\hline 2016 & 95503 & 96602 & 97388 & 2045 & 11048 & 17252 & 24410 \\
\hline 2017 & 93135 & 94538 & 95545 & 2046 & 9243 & 15105 & 22055 \\
\hline 2018 & 90675 & 92407 & 93637 & 2047 & 7680 & 13103 & 19837 \\
\hline 2019 & 88147 & 90200 & 91658 & 2048 & 6278 & 11288 & 17790 \\
\hline 2020 & 85553 & 87925 & 89637 & 2049 & 5067 & 9638 & 15835 \\
\hline 2021 & 82868 & 85572 & 87535 & 2050 & 4058 & 8160 & 14023 \\
\hline 2022 & 80082 & 83147 & 85372 & 2051 & 3183 & 6850 & 12355 \\
\hline 2023 & 77235 & 80647 & 83158 & 2052 & 2472 & 5702 & 10827 \\
\hline 2024 & 74313 & 78068 & 80867 & 2053 & 1887 & 4697 & 9443 \\
\hline 2025 & 71357 & 75418 & 78515 & 2054 & 1433 & 3837 & 8230 \\
\hline 2026 & 68252 & 72698 & 76108 & 2055 & 1060 & 3108 & 7097 \\
\hline 2027 & 65127 & 69903 & 73617 & 2056 & 775 & 2497 & 6093 \\
\hline 2028 & 61937 & 67038 & 71048 & 2057 & 555 & 1987 & 5223 \\
\hline 2029 & 58627 & 64113 & 68463 & 2058 & 392 & 1568 & 4457 \\
\hline 2030 & 55257 & 61130 & 65803 & 2059 & 273 & 1228 & 3768 \\
\hline 2031 & 51940 & 58100 & 63083 & 2060 & 187 & 953 & 3185 \\
\hline 2032 & 48543 & 55015 & 60298 & 2061 & 127 & 735 & 2675 \\
\hline 2033 & 45185 & 51908 & 57478 & 2062 & 85 & 562 & 2250 \\
\hline 2034 & 41770 & 48770 & 54700 & 2063 & 55 & 432 & 1887 \\
\hline 2035 & 38457 & 45613 & 51820 & 2064 & 35 & 325 & 1575 \\
\hline 2036 & 35187 & 42495 & 48907 & 2065 & 23 & 243 & 1313 \\
\hline 2037 & 31952 & 39357 & 45987 & 2066 & 13 & 180 & 1097 \\
\hline 2038 & 28825 & 36250 & 43110 & 2067 & 8 & 135 & 900 \\
\hline 2039 & 25808 & 33217 & 40233 & 2068 & 5 & 100 & 743 \\
\hline 2040 & 22920 & 30282 & 37452 & 2069 & 0 & 72 & 612 \\
\hline
\end{tabular}

Table 5: New nominal series $\left[\boldsymbol{N}^{\prime}\right]=\frac{k}{S V\left(0, T_{0},[\boldsymbol{N}]\right)}[\boldsymbol{N}]$ with $k=4.5 \%$ and $S V\left(0, T_{0},[\boldsymbol{N}]\right)=2.7 \%$ 